\title{
LA POESÍA INGLESA DE LA NATURALEZA EN EL XVIII Y SU INFLUENCIA EN MELÉNDEZ VALDÉS
}

\author{
ÁNGELES GARCÍA CALDERÓN \\ Universidad de Córdoba ${ }^{1}$
}

\begin{abstract}
RESUMEN
'Nature' es una palabra clave a comienzos del siglo XVIII que aparece en todos los campos del conocimiento; el término es repetido una y otra vez por los críticos literarios, y así Pope aconsejará a los poetas: «First follow Nature, and your Judgment frame/By her just Standards, which is still the same», Essay on Criticism. Bajo la influencia de Descartes, de Newton y de Locke, la belleza viene a significar armonía, equilibrio y orden perfecto. Durante el primer cuarto del XVIII la representación de la naturaleza desembocará en la obra de Thomson, Winter. Meléndez leerá al poeta escocés en el original inglés (en su biblioteca consta un ejemplar de Seasons, edición de 1744), y el poema ejercerá bastante influencia sobre algunas composiciones del extremeño, sobre todo en las Odas filosóficas y sagradas.
\end{abstract}

Palabras clave: Poesía campestre, Inglaterra, España, Siglo XviII.

\begin{abstract}
'Nature' is a key word at the beginning of the $18^{\text {th }} \mathrm{c}$. that appear in all fields of knowledge; the term is frequently repeated by literary critics, and thus Pope would advice poets: «First follow Nature, and your Judgment frame/By her just Standards, which is still the same», Essay on Criticism. Under the influence of Descartes, Newton and Locke, the beauty mean harmony, balance and perfect measure. During the fist quarter of $18^{\text {th }} \mathrm{c}$. the representation of nature wild end up in the Thomson's poem Winter. Would read the scottish poet in the english original (in his library there is a sample of the 1744 edition), and the poem wild exert considerable influence on the poet from Extremadura, above all in the Odas filosóficas y sagradas.
\end{abstract}

Key words: Shepherd poetry, England, Spain, 18th century.

\section{INTRODUCCIÓN}

Es ya un lugar común en la literatura inglesa (así como en casi toda la europea) que la renovación del sentimiento de la naturaleza en el siglo XVIII data del 1726, año en el que un joven poeta de Escocia, James Thomson (1700-1748), publica en Londres la primera versión de Winter. Aunque esa

\footnotetext{
${ }^{1}$ Trabajo de investigación realizado con la ayuda de la Fundación Caja Madrid.
} 
afirmación es bastante congruente y lógica, habría que matizar que la obra de Thomson viene precedida por una lenta germinación entre 1700 y 1726, una transformación del sentimiento de la naturaleza con dos líneas preponderantes: la representación de la naturaleza artificiosa que describe los deleites del campo y que se plasma en el género pastoril y en églogas a imitación de Virgilio y Spencer; una segunda variante más rica siguiendo la estela de Las Geórgicas, que se nutre de poemas descriptivos y, además, meditativos $^{2}$. Se trata, en este segundo caso, de poemas escritos en un tono de quietud y retiro en una atmósfera campestre, que tiene su punto de partida a mediados del siglo XVII con Edward Benlowes, Henry Vaughan y Andrew Marvell, para alcanzar su apogeo en la primera mitad del siglo siguiente. La Guerra Civil impulsa a los poetas a retirarse de la vida activa y aislarse en el campo para contemplar las bellezas de la Creación, cantar loas al Creador y esperar serenamente la llegada de la muerte. El tema del retiro o alejamiento al campo adquiere a mediados del XVII una coloración diferente, según los poetas que se ocupan de él y las influencias que sufren. Milton describe en «L'Allegro» y «Il Penseroso» las alegrías de la vida rural y posteriormente de la soledad, poniendo el acento en la contemplación que aporta la serenidad. Por el contrario, el paisaje adquiere en Mildway Fane, Henry Vaughan, Henry More y Andrew Marvell una importancia mucho mayor que en los poetas clásicos: los árboles, los campos, las fuentes parecen cargarse de una vida secreta que pone al poeta en contacto directo con Dios. En este punto es importante la figura del místico de Silesia Jacob Böhme (1575-1624); su obra De Signatura Rerum (1621), de la que se publica en Inglaterra una traducción en 1651, tiene una influencia inmediata sobre los poetas de la época y da un impulso esencial al misticismo. Según Böhme, todo lo que existe tiene una correspondencia o un comercio secreto con el mundo invisible ${ }^{3}$. El mundo exterior es una «signatura» o un reflejo del mundo interior y espiritual; en la medida en que Dios se manifiesta en la naturaleza el paisaje adquiere una importancia creciente en la poesía: la naturaleza se convierte en un paraíso terrestre en el que el poeta se refugia y experimenta un placer casi sensual, que se transforma pronto en éxtasis místico. Así, las tendencias ocultas que se constatan en la obra de Marvell

\footnotetext{
${ }^{2}$ Las raíces de este tipo de poemas podemos hallarlas en Charles Cotton (1630-1687): «An Ode to Winter» y «The Retirement», Andrew Marvell (1621-1678): «The Garden» y «The Mower» (The Mower Against Gardens), y John Milton (1608-1674): «L'Allegro» e «Il Penseroso». Por lo que respecta a los poemas meditativos, ya ha sido resaltada por VALENTE, Jose Ángel, «Luis Cernuda y la poesía de la meditación», La Colmena

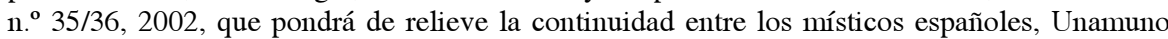
y Cernuda en este tipo de poesía «meditativa» que proviene de la mística española.

3 Teoría que más tarde pondrá de moda el sueco Emmanuel Swedenborg, y que será toda la base de la estética simbolista, a partir del famoso soneto de Baudelaire, «Correspondances».
} 
y Benlowes provienen en gran parte de estas influencias; podemos ver una clara identificación del hombre con la naturaleza y un verdadero fervor espiritual en dos poemas de Marvell: «The Garden» y «Upon Appleton House»: el poeta está enamorado de la naturaleza porque ésta le refleja la imagen de Dios. El color verde, 'this lovely green', que descubrimos continuamente en sus poemas, aparece como el reflejo de la presencia divina en la naturaleza, como podemos apreciar en la transcripción del primer poema y en las cuatro primeras estrofas (de las 97 de que consta) del segundo:

THE GARDEN

How vainly men themselves amaze

To win the palm, the oak, or bays;

And their uncessant labors see

Crowned from some single herb or tree,

Whose short and narrow-verged shade

Does prudently their toils upbraid;

While all the flowers and trees do close

To weave the garlands of repose.

Fair Quiet, have I found thee here,

And Innocence, thy sister dear!

Mistaken long, I sought you then

In busy companies of men:

Your sacred plants, if here below,

Only among the plants will grow;

Society is all but rude,

To this delicious solitude.

No white nor red was ever seen

So amorous as this lovely green;

Fond lovers, cruel as their flame,

Cut in these trees their mistress' name.

Little, alas, they know or heed,

How far these beauties hers exceed!

Fair trees! wheresoe'er your barks I wound

No name shall but your own be found.

When we have run our passion's heat,

Love hither makes his best retreat:

The gods who mortal beauty chase,

Still in a tree did end their race.

Apollo hunted Daphne so,

Only that she might laurel grow,

And Pan did after Syrinx speed,

Not as a nymph, but for a reed.

What wondrous life is this I lead!

Ripe apples drop about my head;

The luscious clusters of the vine

Upon my mouth do crush their wine;

The nectarine and curious peach 
Into my hands themselves do reach; Stumbling on melons as I pass, Insnared with flowers, I fall on grass.

Mean while the mind, from pleasure less, Withdraws into its happiness; The mind, that ocean where each kind Does straight its own resemblance find; Yet it creates, transcending these, Far other worlds, and other seas; Annihilating all that's made To a green thought in a green shade.

Here at the fountain's sliding foot, Or at some fruit-tree's mossy root, Casting the body's vest aside,

My soul into the boughs does glide;

There like a bird it sits and sings,

Then whets and combs its silver wings;

And, till prepared for longer flight, Waves in its plumes the various light.

Such was that happy garden-state,

While man there walked without a mate:

After a place so pure and sweet, What other help could yet be meet!

But 'twas beyond a mortal's share

To wander solitary there;

Two paradises 'twere in one

To live in Paradise alone.

How well the skillful gard'ner drew Of flowers and herbs this dial new; Where from above the milder sun Does through a fragrant zodiac run; And, as it works, th' industrious bee Computes its time as well as we. How could such sweet and wholesome hours Be reckoned but with herbs and flowers!

UPON APPLETON HOUSE, TO MY LORD FAIRFAX

$$
\text { I }
$$

Within this sober Frame expect

Work of no Forrain Architect;

That unto Caves the Quarries drew,

And Forrests did to Pastures hew;

Who of his great Design in pain

Did for a Model vault his Brain,

Whose Columnes should so high be rais'd

To arch the Brows that on them gaz'd. 
II

Why should of all things Man unrul'd

Such unproportion'd dwellings build?

The Beasts are by their Denns exprest:

And Birds contrive an equal Nest;

The low roof'd Tortoises do dwell

In cases fit of Tortoise-shell:

No Creature loves an empty space;

Their Bodies measure out their Place.

\section{III}

But He, superfluously spread,

Demands more room alive then dead.

And in his hollow Palace goes

Where Winds as he themselves may lose.

What need of all this Marble Crust

T'impark the wanton Mose of Dust,

That thinks by Breadth the World t'unite

Though the first Builders fail'd in Height?

\section{IV}

But all things are composed here

Like Nature, orderly and near:

In which we the Dimensions find

Of that more sober Age and Mind,

When larger sized Men did stoop

To enter at a narrow loop;

As practising, in doors so strait,

To strain themselves through Heaven's Gate.

Conforme va avanzando el siglo el tema del retiro en el campo pierde entusiasmo para adquirir características de más mesura y equilibrio; el misticismo cede el paso a un epicureismo más inocente. A comienzos del XVIII, a pesar de las ocupaciones que propician las luchas entre 'whigs' y 'tories', el atractivo de Londres, la intensa vida social, la multiplicación de los 'clubs'..., los poetas siguen inmersos en la vida política y proyectan en la naturaleza sus aspiraciones secretas, su nostalgia de la Edad de Oro; su deseo de escapar de una sociedad utilitaria, competitiva, dedicada cada vez más al comercio y a los bienes materiales los lleva a refugiarse en el campo. Éste les ofrece un 'escapist urge' y unos paisajes idílicos, que se plasman en la pastoral, conforme a la estética de lo bello heredada del siglo XVII y definida por Addison en su Spectator (n. ${ }^{\circ}$ 412) y por Burke en su tratado The Origin of our Ideas of the Sublime and Beautiful. Según Addison, la belleza se encuentra en los objetos dulces, coloreados y alegres, expandiendo sobre el campo una 'satisfacción secreta y un gran contento en la imaginación'. Burke asocia la belleza a lo pequeño y a la dulzura: el pelaje de los animales, la pluma de los pájaros, las hojas brillantes, los ríos y la inclinación 
de las colinas; según él, el mirto, la viña y el jazmín simbolizan la finura y la belleza, mientras que el roble, el fresno y el olmo son majestuosos y sublimes.

La mayor parte de los poetas del XVIII alaban los encantos del retiro al campo, al que hay que amar por sí mismo (escribirá Cowper), por su silencio y su sombra. El retiro anima la soledad que conduce a la contemplación; el vocabulario que da título a los poemas de exaltación de la vida rústica es bastante amplio: 'Solitude', 'Retirement', 'Meditation', 'Contemplation', 'Contentment', 'The Wish', 'The Choice', etc. Sus autores desprecian la corte, la agitación de las ciudades, la masa, la ambición, la riqueza, los honores y otras vanidades.

Los poemas que se inspiran en la pastoral expresan, con más o menos fortuna, este ideal de belleza, y entre los más representativos por orden cronológico hallamos los siguientes ejemplos: The Choice (1700) del reverendo John Pomfret ${ }^{4}$, Upon the Hurricane (1704) de Anne Finch ${ }^{5}$, The BirthNight (1705) de Edmund Arwaker ${ }^{6}$, Cyder (1708) de John Philips ${ }^{7}$, A Winter-

\footnotetext{
${ }^{4}$ Pastor anglicano considerado uno de los precursores de la denominada «Graveyard School» (Escuela o Poesía 'de las tumbas', 'de los sepulcros', 'de los cementerios', etc.), por su tratamiento de la emoción, la voluptuosidad, las lágrimas, y se complace en el culto de la tristeza, sentimiento que se paladea por la propia satisfacción que produce. En un ensayo pindárico en diez estrofas, A Prospect of Death, Pomfret espera aterrorizar al pecador y reconducirlo por el camino recto al presentarle la muerte con colores sombríos, incluso siniestros. El tono del poema recuerda al de las elegías puritanas del XVII y anuncia la atmósfera de las Nights de Young. The Choice es el poema por el cual ha pasado el escritor a la historia de la literatura inglesa, y que hará escribir al Dr Johnson en 1779: «Perhaps no composition in our language has been oftener perused», en The Lives of the most Eminent English Poets, 10 vols., Dublín, 1777-81 (prefaces, Biographical Notes and Critical, to the Works of the English Poets; ediciones revisadas: 1783, 1905, 1972, ed NY J.P. Hardy).

${ }^{5}$ Anne Finch, Condesa de Winchilsea (1661-1720), de nombre literario 'Ardelia', es conocida por su discreción y lirismo delicado lleno de finura y sentido poético que, sin embargo, no excluyen la ironía y el humor en su obra; "A Pindaric Poem upon the Hurricane in November 1703, referring to this Text in Psalm 148», éste es el título completo, es un poema de 303 versos en el que se relata un acontecimiento real con una precisión y vigor que rara vez hallamos entre las poetisas de esa época: describe con simpatía la resistencia que oponen los árboles a los elementos desencadenados y el combate entre los propios vientos. William Broome (1689-1745), el colaborador de Pope, destaca también en la descripción de la furia elemental de la naturaleza, que asocia a la muerte, en «A Poem on the Seat of War in Flanders» (1710).

${ }^{6}$ Edmund Arwaker (1655-1730), en su pastoral es sensible al silencio terrorífico y a la grandeza solemne de la noche. El poeta se muestra en comunión con el paisaje nocturno ya que éste tiene correspondencias sutiles con la emoción que el propio poeta experimenta.

7 John Philips (1676-1709) sufrirá la influencia de Las Geórgicas, cuyo tema principal retoma: la actividad del granjero está estrechamente ligada a la vida del estado, la riqueza del país depende de su equilibrio político. El poema es una 'geórgica' de tipo topográfico, como Dryades (1712) de William Diaper y Windsor Forest (1713) de Pope.
} 
Piece (1709) de Ambrose Philips ${ }^{8}$, Rural Sports (1713) y The Sheperd's Week (1714) de John Gay ${ }^{9}$, Windsor-Forest (1713) de Alexander Pope ${ }^{10}$. El poema de Pope es un microcosmos del universo inglés, aunque en la línea de la pastoral la obra enriquecerá el género al integrar en ella al hombre, dando paso a un tipo de poesía diferente a la pastoral, mucho más descriptivo y en el que la vida animal transmite una ternura real que se hará más ostensible en Thomson.

\section{WINTER DE JAMES THOMSON}

Winter es compuesto en 1725, tras la llegada de Thomson a Londres. El poeta no ha previsto escribir un largo poema religioso y filosófico, pues, estimulado por los versos de Riccaltoun, A Winter's Day, se contenta con dejar sobre el papel impresiones sueltas, que reunirá poco a poco como las piezas de un puzzle, adaptándolas y organizándolas en un todo coherente. La versión original de Winter es concebida según el modelo de «Il Penseroso». Se trata de un poema a la vez descriptivo y reflexivo, que es llevado a cabo en el tiempo de su estancia en East Barnet, donde es preceptor del hijo mayor de lord Binning. A pesar de la amabilidad con que es tratado, siente la nostalgia de su país natal y se acuerda con emoción de los lugares áridos y salvajes de Escocia, que han marcado su vida.

James Thomson anuncia el triunfo de los poemas a la naturaleza con su temprano Winter (1726), y a partir de él se experimenta una floración poética que refleja un contacto más íntimo con la Naturaleza. La obra completa, The Seasons (1726-30), es un poema descriptivo de 5.541 versos blancos, de clásica sencillez, que presenta una pintura del paisaje según la

\footnotetext{
${ }^{8}$ Ambrose Philips (1674-1749), apodado por Pope y Swift 'Namby Pamby' por sus versos almibarados; sus pastorales sugieren un cambio de tono y de atmósfera al estar coloreadas por la emoción e impregnadas de preciosismos, dulzuras y melancolía, con un vocabulario especial lleno de palabras como 'moan', 'pain', 'tear', 'beauteous', 'fair', 'gentle', 'soft', 'smooth', 'sweet', 'piteous', 'sad', 'unhappy', etc., términos que son clichés de la «poetic diction» más usual; a pesar de todo, el autor no carece de talento para crear el clima apropiado.

9 John Gay (1658-1732), The Shepherd's Week es una pastoral burlesca en las que el autor se burla de las pastorales de Ambrose Philips. Es también un preciso cuadro de las costumbres, de los hábitos, alegrías, inquietudes y supersticiones de los campesinos de la época. El autor alía en la obra lo natural a lo sencillo, aunque las descripciones de la naturaleza se limiten a algunos rasgos discretos y rápidos. En John Gay se inspirará Allan Ramsay (1686-1758) para sus dos pastorales: Patie and Roger (1720) y Jennie and Meggie (1723)

${ }^{10}$ Windsor Forest es la prolongación natural de las pastorales, aunque está impregnado del tono patriótico de Las Geórgicas, afirmando el propio escritor que escribe siguiendo la tradición de Virgilio. Se inspira, además, en la poesía loco-descriptiva que había puesto de moda John Denham en Cooper's Hill (1642).
} 
rotación anual, en la que alternan las distintas circunstancias de la vida. Aparece por primera vez en la poesía moderna el verdadero sentimiento de la naturaleza, y en cualquiera de las estaciones se la halla descrita con sincera vitalidad. Thomson aportaba a la poesía de su tiempo elementos con los que jamás se había soñado anteriormente, adelantándose en más de tres décadas a Rousseau ${ }^{11}$. En la obra de Thomson se puede percibir la sensación lúgubre y desolada de la landa surcada de riachuelos de su país natal. En invierno la naturaleza adquiere allí un aspecto severo, teñido de grandeza y de poder; de ahí que se entregue a una meditación otoñal, cuya tonalidad velada y melancólica anuncia el clima elegíaco de los poemas de William Collins (1721-1759) y de Thomas Warton (1728-1790). En la primera versión se respira un perfume de autenticidad que ya no se sentirá tan claramente en la de 1730 o en la de 1746. El poema está impregnado de la profunda ternura que todo escocés siente por sus colinas natales y que se puede percibir en Alan Ramsay (1686-1758), Robert Fergusson (1750-1774), Robert Burns (1759-1796) o Robert Louis Stevenson (1850-1894). La tristeza de la estación está en armonía con el estado del alma del poeta, que atraviesa en 1725 un período difícil de su existencia y una crisis espiritual: desarraigado, exiliado en Inglaterra, está preocupado por su futuro y muy afectado por la muerte brutal de su madre, ocurrida después de su marcha. Winter no es sólo una descripción objetiva de la naturaleza; es también el reflejo exacto de la inquietud del poeta, la expresión subjetiva de su melancolía.

Basándose en estas premisas personales, Thomson 'atrapa' la naturaleza en perpetuo devenir, confiriéndole un carácter cíclico; el poeta evoca en algunos versos nostálgicos el declinar de los hermosos días, la caída de las hojas y de los frutos, el color apagado de las flores que pierden su brillo y abandonan sus 'adornos soleados'. Pero el poeta escocés no se limita a anotar vistas estáticas o descomponer arbitrariamente la realidad del mundo, diferentes en cada momento. Cada escena individual está compuesta de elementos evanescentes que se funden uno en otro en el mismo momento en que se esfuerza en fijarlos. Es también sensible a la extrema movilidad de las formas y de los colores, fijando la mirada en los aspectos variables, en los matices sutiles más bien que en los paisajes precisos y estáticos. De este modo, describe con complacencia los movimientos de las nubes; éstas, por sus formas, colores, su apariencia blanda o elástica y su movilidad, dan al cielo de Inglaterra o de Escocia una vida, una animación que hacen su contemplación mucho más agradable y poética. Thomson evoca con trazos rápidos la masa oscura de nubes nocturnas, o bien el cielo pesado y gris que preludia la tempestad o la nieve; en este último caso, el poeta transmite al

11 Que expresará en su Nouvelle Hélö̈se (1761), al exaltar la naturaleza en Clarens, parecidas emociones y sentimientos. 
lector una sensación muy auténtica de agobio, basada en el cielo bajo, que parece pesar sobre el mundo como una capa de plomo. La niebla de noviembre parece deslizarse sobre los pantanos y las orillas de los ríos, modificando el paisaje y llenándolo de bruma, lo que le propicia un aspecto a la vez inquietante y misterioso. Se diría que el cielo y la tierra se ahogaran en las tinieblas opacas, que contrastan con el claro de luna y el brillo del cielo estrellado.

En general, la naturaleza se muestra vibrante, animada por una vida secreta de la que el escritor traduce las menores agitaciones con la ayuda de verbos muy precisos, que reflejan un movimiento imperceptible, una ligera vibración: «Humid evening gliding 0'er the Sky», «Cluster the rolling Fogs», «The fair Moon... rides sublime», «the waving Shades», «abundant Dews... Fall», «tremble the transluced Gems», «quivering, seem to fall away, yet cling», etc.

En el prólogo de Lyrical Ballads ya señalaba Wordsworth que su capacidad se basaba en observar la naturaleza detenidamente, plasmando en la descripción hasta el más mínimo detalle.

\section{Thomson examin'd every drop that glistens That glistens on the thorn; each leaf survey'd Which Autumn from the rustling forestshakes And mark'd its shape, and trac'd in the rude wind. Its eddying motion.}

Tan fuerte será el impacto de la obra, no solamente en Inglaterra, sino también en Europa, que la obra completa, The Seasons, será traducida hacia la mitad del siglo al alemán y al francés, convirtiéndose en una fuerza activa en la literatura europea, no siendo extraño que afirme el biógrafo francés de Thomson:

Il est peu d'œuvres qui aient eu sur la littérature de l'Angleterre une influence plus puissante que les Saisons; il n'en est pas peut-être qui en ait eu à l'étranger une aussi grande ${ }^{12}$.

En Francia, Thomson será imitado por Jean-François de Saint-Lambert (Les Saisons) ${ }^{13}$, Jean-Antoine Roucher (Les Mois), Jacques Delille y buena

${ }^{12}$ MoRel, Léon, James Thomson, sa vie et ses exuvres, Paris, Hachette, 1895, p. 192.

${ }^{13}$ La siguiente descripción de una tempestad (perteneciente a L'Été quedará durante mucho tiempo en Francia como uno de los modelos del género en los manuales escolares del siglo XIX:

«D'un tonnerre éloigné le bruit s'est fait entendre:

Les flots en ont frémi, l'air en est ébranlé,

Et le long du vallon le feuillage a tremblé

Les monts ont prolongé le lugubre murmure,

Dont le son lent et sourd attriste la nature.

Il succède à ce bruit un calme plein d'horreur,

Et la terre en silence attend dans la terreur». 
parte de los poetas franceses de la segunda mitad de siglo: Nicolas-Germain Léonard, Jean-Pierre Louis de Fontanes, André Chénier -el poeta más grande del siglo- Bernis ${ }^{14}$, Colardeau, Rosset, Lemierre, Lézay-Marnésia, etc. ${ }^{15}$

En España, Thomson será traducido por Benito Gómez Romero ${ }^{16}$ e imitado por Mor de Fuentes, con Las estaciones (1819), e influenciará a Meléndez Valdés y Cienfuegos, éste en menor medida.

Hacia 1730-40, cuando el clasicismo se halla aún en floreciente vitalidad, despierta en Inglaterra un movimiento distinto, opuesto a la modalidad literaria establecida, manifestándose otras aspiraciones que debían culminar en el Romanticismo. Los objetivos de la nueva tendencia se sintetizan en la Naturaleza como motivo estético, el sentimentalismo moral, el estímulo del espíritu filantrópico y religioso, además del amor al campo, sentimiento natural en Inglaterra. Poemas representativos de esta tendencia son los que se ocupan de la «natural description», en la vía abierta por Thomson: «The Enthusiast» (1744) y «Ode to the Evening» (1746) de Joseph Warton, «Ode to Evening» (1747) de William Collins, «Ode on the Spring» (1748) de Thomas Gray. Con Grey y los escritores de la «Graveyard School» (Young, Blair, Hervey, Carter...) la vía de la poesía cambia a unos tonos mucho más lúgubres.

\section{INFLUENCIA DE ESTA POESÍA EN MELÉNDEZ VALDÉS}

El triunfo definitivo en España de esta tendencia será más tardío. En noviembre de 1794, encontramos en el Diario de Madrid un anónimo Discurso sobre la poesía bucólica, donde leemos:

Ninguno de los modernos ha comprendido tan bien como Gessner toda la extensión del género bucólico, sus poesías de este género son el más bello modelo que se puede presentar para la imitación. Allí se puede ver la gran variedad de asuntos, propios de la poesía pastoril, que hasta ahora no se había tocado; el estilo es el más propio: los sentimientos, las imágenes, todo es pastoril y todo encanta ${ }^{17}$.

En España, como en toda Europa, el influjo francés es dominante, llegando a producir una ola de galomanía; aunque el siglo XVIII debe aún, incluso

14 François Joachim de Pierre de Bernis (1715-1794). Las obras publicadas en vida justifican el apelativo que Voltaire le adjudicó: 'Babet la bouquetière'.

15 Para esta influencia es fundamental el libro de CAMERON, Margareth M., L'Influence des «Saisons» de Thomson sur la poésie descriptive en France (1759-1810), Paris, Honoré Champion, 1927.

16 Thomson, James, Las estaciones del año, poema de Jayme Thompson [sic], traducido por D. Benito Gómez Romero, presbítero, Madrid, Imprenta Real, 1801, 2 vols.

17 Cit. por CANO, J. L., «Gessner en España», Revue de Littérature Comparée, XXXV, 1961, p. 50. 
en sus críticas, bastante a España, manteniendo los grandes autores del Siglo de Oro su prestigio, la influencia francesa es indiscutible en autores y obras concretas: Boileau (Art poétique) en Iriarte, La Fontaine (Fables) en Samaniego, Montesquieu (Lettres persanes) en Cadalso; en el pensamiento y estética literaria del escritor o la corriente: Rousseau en Jovellanos, Voltaire (Le Siècle de Louis XIV) y el Enciclopedismo en la cultura española; en las traducciones de autores franceses: Le Tourneur y sus versiones de Young, de Macperson-Ossian y de otros poetas ingleses. Hay una gran afluencia de libros franceses en los que domina por momentos la razón, aunque algo más tarde surja otra corriente, que se basa en el sentimiento (Rousseau y su Nouvelle Héloïse); son éstos los dos polos por los que se mueve la Ilustración. Respecto al estilo, es el concepto de belleza el que preside las artes, pero es un concepto de belleza intemporal. Lo que se debe imitar es lo bello de la naturaleza, y da igual el tiempo.

La poesía pastoril tendrá un gran desarrollo, ya que gran parte de los poetas españoles se reúnen en «Arcadias poéticas», disfrazándose su personalidad y las de sus amadas bajo nombres pastoriles. Se vuelve a repetir, en mero juego literario, la afición por la vida campestre. Unas veces el tema está ligado más a la tradición rococó, y entonces se desarrolla en bailes pastoriles y juegos al aire libre. Pero también podemos observar cómo lo pastoril se carga del pensamiento ilustrado. En esos casos, se menosprecia realmente a la ciudad y se alaba la vida primitiva y virtuosa de campesinos y pastores, o se busca en la naturaleza un refugio para las penas. En el tratamiento de lo pastoril se deben diferenciar muchos matices, que irían desde lo más intrascendente a lo más ilustrado o ideológico del periodo siguiente ${ }^{18}$.

La bucólica dieciochesca toma esencialmente dos direcciones, representadas en la égloga y el idilio. Corresponden, respectivamente, a la valoración de los modelos clásicos (Virgilio-Garcilaso) y los modelos modernos (Thomson-Gessner). La égloga significa la resurrección de las raíces clásicas y renacentistas. Gran parte de los poetas neoclásicos escribieron églogas. En 1779 convoca la Real Academia un concurso de poesía bajo el lema de Elogio de la vida campestre. A él concurren muchos poetas, y el primer premio es para Meléndez Valdés con su égloga Batilo, quedando en segundo lugar Iriarte con La felicidad de la vida del campo $^{19}$. En Meléndez se

18 Para este aspecto concreto, véase: PALACIOS FERNÁNDEZ, Emilio, «Los poetas de nuestro Siglo de Oro vistos desde el XVIII», II Simposio sobre el P. Feijoo y su siglo, Oviedo, 1976.

19 No aceptó de buen grado el poeta canario la decisión académica y la envidia lo llevó a escribir su polémico folleto Reflexiones sobre la égloga intitulada Batilo, donde, amén de un minucioso análisis estilístico de la égloga de Meléndez, inutilizado en su mayor parte por su animadversión, hay una disquisición teórica sobre la égloga. es curioso anotar que el Meléndez que supo mostrar sus ideas ilustradas al hablar de aradores, segadores o vendimiadores, no pudo nunca desprenderse de la hojarasca pastoril. La réplica a 
sigue así la visión tradicional de la pastoral clásica, aunque adornada en algunos momentos con ideas que nos hablan de un nuevo espíritu.

Juan Meléndez Valdés (1754-1817) ${ }^{20}$ cultivó bajo el influjo de Pope la poesía filosófica, como en «La gloria de las artes», pero al mismo tiempo su delicada inspiración produjo numerosos poemas líricos, anacreónticos y amorosos, bajo la forma de églogas, romances o letrillas: sus Poesías (1785), varias veces reeditadas, incluyen algunas de las piezas más populares de la literatura castellana de la época. Los rasgos más acusados del carácter y de la obra de Meléndez Valdés ('Dulce Batilo') son su afectividad y sensibilidad, entendidas no sólo como propensión al sentimentalismo, sino también como apertura y permeabilidad a las distintas influencias humanas, políticas y literarias. Este último aspecto es el que le permite estar abierto a las diversas corrientes poéticas de su tiempo y reflejarlas en las distintas líneas en las que se desarrolla su obra. Junto con la suave poesía anacreóntica y bucólica que le ha dado la fama, conviven en la obra de Meléndez la poesía civil, filosófica y moral características del Neoclasicismo ${ }^{21}$. Si la poesía anacreóntica fue una de las direcciones más frecuentadas por los poetas dieciochescos, ninguno como Meléndez la prodigó tanto en cantidad y calidad ${ }^{22}$. Poesía de los sentidos y del amor, inspirada en modelos clásicos grecolatinos, y ambientada en el marco de una naturaleza idealizada, amable y tópica, sus Odas anacreónticas constituyen la mejor manifestación de tal género. La visión de la naturaleza va evolucionando en estas composiciones desde

Iriarte le sería dada por el antiguo contertulio de Salamanca Forner con su Cotejo de las Églogas, quien, después de expresar su teoría de la literatura, se pone de parte de Meléndez:

«Pastores, gente sencilla, zagales simples y apasionados requiere sencillez de su estado. Discursos puros, y naturales que dejan el sabor de la rusticidad y el olor de la simplicidad de los que pronuncian, atribuye a las personas de la égloga el que traslada a sus versos la verdad de la Naturaleza» (FoRNER, J. P., Cotejo de las Églogas, ed. de F. Lázaro, Salamanca, 1951, p. 32).

${ }^{20}$ Como bien afirma Emilio Palacios Fernández (autor asimismo de las ediciones más recientes sobre Meléndez Valdés), la mejor biografía de Meléndez Valdés es el documentado trabajo del hispanista francés Georges Demerson (1971), complementado en los últimos tiempos con la Biografía (1996) de Antonio Astorgano Abajo, autor también de varios artículos sobre Meléndez.

${ }^{21}$ Podemos valorar aún la división que llevó a cabo Pedro Salinas en la edición de las poesías de Meléndez Valdés en 1925: «Poesía de la Naturaleza» (Odas anacreónticas, Églogas e Idilios, «sentimentalismo»(Epístolas), «Tendencia filosófica».

${ }^{22}$ Sabido es que las poesías que solían atribuirse a Anacreonte de Teos, poeta de corte y cantor del vino y de los amores en el siglo VI a. de J-C., son en realidad imitaciones nacidas en la Alejandría helenística hacia el comienzo de la era cristiana. Se publicaron en París en 1554; texto, traducciones e imitaciones se difundieron rápidamente a través de toda Europa, manteniéndose en el parnaso hasta principios del XIX. La primera traducción española del supuesto Anacreonte parece haber sido la de Quevedo, anterior a 1610 pero inédita hasta 1794. La más importante, por sus cualidades poéticas y por la influencia que ejerció, fue la de Esteban Manuel de Villegas, cuyas Eróticas (1618) forman el Libro IV de la Parte Primera El Anacreonte, «traducido en la misma cadencia en que está el griego». 
la contemplación puramente descriptiva hasta una interpretación melancólica y sentimental que aparece en las Elegías morales y anticipa ya el enfoque romántico. Esta tendencia se va acentuando en la madurez del poeta y se concreta en sus últimos poemas

La biblioteca de Meléndez Valdés es reveladora de todo lo que se dice en su biografía de las influencias foráneas; llegó a estar formada por 352 títulos y 1237 volúmenes, de los cuales 199 en francés y 12 en inglés ${ }^{23}$.

Por lo que se refiere a la literatura francesa los nombres más conocidos son los de Montaigne, el abate Henry, La Bruyère, Malebranche, Marmontel, Pascal, Jean y Louis Racine, Saint-Évremond, Montesquieu, Rousseau, SaintLambert (Les Saisons) ${ }^{24}$, Voltaire y Roucher (Les Mois).

En lengua inglesa encontramos los nombres de Addison, Chambers y su famosa Enciclopedia, Clarke, y, sobre todo, Milton, Shakespeare, Thomson (The Seasons, edición de 1744) y Young, que figuran en ediciones originales; Pope, a quien lee y admira el poeta, está representado por una edición bilingüe franco-inglesa; el texto inglés de las Noches de Young está acompañado por la traducción de Le Tourneur. En cuanto a pensadores o historiadores (Ferguson, Gibbon, Hume, Hutcheson, Robertson, Adan Smith), el poeta los lee, al igual que a Richardson (Clarissa Harlowe), en traducción francesa.

Observamos, pues, un predominio indiscutible de libros franceses en la biblioteca de Meléndez: más del $56 \%$ de los títulos y más del $60 \%$ de los volúmenes. En el único período en que la verificación nos ha sido posible, años 1778-1782, comprobamos que esta proporción no se debe al azar, ya que las compras imputables con seguridad al poeta sitúan esta proporción entre el 70 y el $75 \%$. Es, pues, absolutamente legítimo hablar de un «afrancesamiento intelectual» de Meléndez, lo que se demuestra por la admiración y el placer sin límites que experimenta por los textos franceses ${ }^{25}$, y que pone de relieve en sus cartas con Jovellanos. Esta admiración se extiende a todos

${ }^{23}$ Cfr.: ENCISO, Luis Miguel, «La Biblioteca de Meléndez Valdés», Barroco e Ilustración en la Bibliotecas Privadas españolas del siglo XVIII, Discurso de ingreso en la Real Academia de la Historia el día 17 de marzo de 2002, Madrid, 2002, pp. 183-186.

${ }^{24}$ Saint-Lambert, junto con Thomson y Gessner, posiblemente fuera uno de los autores que con más cariño y gusto leyera Meléndez; cosa nada extraña puesto que el francés al adaptar la obra de Thomson fue el poeta más famoso de su tiempo. Es muy probable que el autor español leyera una edición de Les Saisons publicada en Londres y reeditada varias veces con posterioridad a 1769, con un exergo del escritor alemán Wieland: «Puissent mes chants être agréables à l'homme vertueux et champêtre, et lui rappeler quelquefois ses devoirs et ses plaisirs!». En el amplio «Discours préliminaire» Saint-Lambert redacta una verdadera poética de la poesía campestre.

25 Aspecto éste que ha sido puesto de relieve por DEL PRADO, Javier, «La imagen de Francia en el diálogo epistolar de Jovellanos, Meléndez Valdés y Moratín», Homenaje al Prof. Jesús Cantera, Madrid, Servicio de Publicaciones Universidad Complutense, 1997, pp. 243-256. 
los ámbitos de la lectura, ya sea literaria, filosófica o relativa a temas de jurisprudencia. Veamos algunos párrafos de Meléndez, en los que alude incluso al poema de Thomson imitado por Saint-Lambert:

Es cierto que El amor enamorado no puede compararse con el mismo pensamiento, tratado ya en prosa por el señor de Montesquieu después de su Templo de Gnido. Creo que habrá usted leído a este gran hombre, aún en estos dos pasatiempos, y por tanto dejo de alabarlos (Meléndez a Jovellanos, 24-VIII1776) ${ }^{26}$

He acabado de leer el poema de la religión de Racine. Me ha gustado infinito y he animado a nuestro Delio [Fray Diego Tadeo] a su traducción. Aún no me han traído el poema de Las estaciones de Madrid; yo celebro que Vd. guste y que Los siglos de la literatura se engañen algo. También los he visto y no me parece hacen el mérito que deben a los más modernos. El Belisario dicen que sólo es aguantable en el primer capítulo, y yo hallo que no es inferior a los demás (Meléndez a Jovellanos, 6-X-1977) ${ }^{27}$.

He logrado el curso de estudios del abate Condillac, que son dieciséis tomos. Llevo leídos los dos primeros, que son Arte de hablar y de escribir. Me gustan mucho, y toda la obra, por el plan de ella, me parece excelente (Meléndez a Jovellanos, 16-VII-1780) ${ }^{28}$.

Podemos apreciar la gran admiración, no exenta de engolamiento, por la cultura francesa en Meléndez Valdés: Francia tiene una tradición estética de la que carecen los españoles:

Estoy también leyendo las reflexiones críticas sobre la poesía y la pintura del abate Dubos, que me gustan muchísimo, y juzgo escritas con gran juicio. A nosotros nos hace, a mi ver, falta esta clase de escritos, que dan al mismo tiempo las reglas del buen gusto y forman el juicio con lo ajustado de sus reflexiones. Los franceses abundan en ello al paso que nosotros carecemos de todo (Meléndez a Jovellanos, 6-II-1779).

La admiración y búsqueda de todo lo francés hace emerger en el pensamiento del poeta español el modelo inglés, que se va abriendo hueco por la vía francesa. Comienza a leer a Pope, que le entusiasma, pero lo hace en edición francesa, igual que a Locke; no sólo no niega esto, sino que en un momento dado confiesa: «estoy aprendiendo la lengua inglesa: la gramática de que me sirvo es la inglesa-francesa de Mr. Peyton». Es curioso observar la predisposición sentimental que Meléndez Valdés tenía por el inglés, aún

\footnotetext{
${ }^{26}$ Los dos pasatiempos de Montesquieu son; Le temple de Gnide (1725) y Céphise et l'amour, texto añadido al anterior en su reedición de 1743.

${ }^{27}$ El Poema de la religión es: La religion-poème (1642), Los siglos de literatura se refiere al título del polígrafo Sabatier de Castre: Les Trois Siècles de la littérature ou Tableau de l'esprit de nos écrivains depuis François $I^{e r}$ jusqu'en 1772, obra que gozó de un gran éxito y se reeditó seis veces hasta 1800 . Belisario es el Bélisaire de Marmontel (1767)

${ }^{28}$ Se refiere a la obra Cours d'études pour l'instruction du Prince de Parme, Parma, 1775.
} 
sin conocerlo. "ya desde muy niño tuve a esa lengua y a su literatura una inclinación excesiva, y uno de los primeros libros que me pusieron en la mano y aprendí de memoria fue el de un inglés doctísimo. Al Ensayo sobre el entendimiento humano debo y deberé toda mi vida lo poco que sepa discurrir» (Meléndez a Jovellanos, 3-VIII-1776).

Descendiendo a ejemplos concretos en los que se plasme la influencia de la 'poesía de la naturaleza' inglesa del XVIII, y recogiendo los aspectos melancólicos en los que la naturaleza no se contenta con servir de decorado a la emoción del poeta, sino que una y otra van estrechamente ligadas, posibilitando que el decorado melancólico provoque un repliegue sobre sí mismo y posibilite la meditación solitaria, que engarzará con los temas nostálgicos del prerromanticismo, hallamos el bellísimo romance «El árbol caído», donde se trata al árbol como a un ser humano 'hollado, horroroso, yerto'; el retiro al campo, lejos de vanidades y honores, queda perfectamente plasmado por la silva VII de Meléndez Valdés «Mi vuelta al campo». En una oda que tiene como tema central la naturaleza («La noche de invierno») es muy clara la influencia de Anne Finch y su «A Pindaric Poem upon the Hurricane in November 1703», al describir la tempestad, el rayo y la desolación. Veamos el comienzo de los dos poemas:

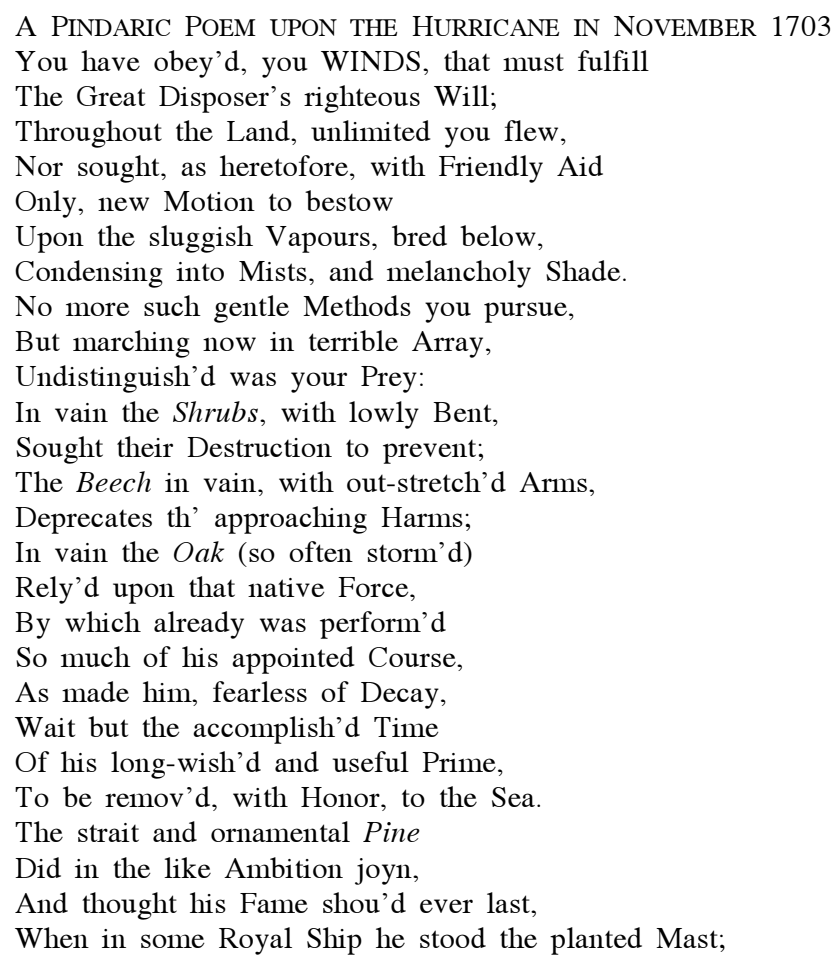


And shou'd again his Length of Timber rear, And new engrafted Branches wear

Of fibrous Cordage and impending Shrouds,

Still trimm'd with human Care, and water'd by the Clouds.

But oh, you Trees! who solitary stood;

Or you, whose Numbers form'd a Wood;

You, who on Mountains chose to rise,

And drew them nearer to the Skies;

Or you, whom Valleys late did hold

In flexible and lighter Mould;

You num'rous Brethren of the Leafy Kind,

To whatsoever Use design'd,

Now, vain you found it to contend

With not, alas! one Element; your Friend

Your Mother Earth, thro' long preceding Rains,

(Which undermining sink below)

No more her wonted Strength retains;

Nor you so fix'd within her Bosom grow,

That for your sakes she can resolve to bear

These furious Shocks of hurrying Air;

But finding All your Ruin did conspire,

She soon her beauteous Progeny resign'd

To this destructive, this imperious Wind,

That check'd your nobler Aims, and gives you to the Fire...

LA NOCHE DE INVIERNO

¡O! ¡cuan hórridos chocan

Los vientos! ¡o que silbos,

Que cielo y tierra turban

Con soplo embravecido!

Las nubes concitadas

Despiden largos ríos,

$\mathrm{Y}$ aumentan pavorosas

El miedo y el conflicto.

La luna en su albo trono

Con desmayado brillo

Preside a las tinieblas,

En medio de su giro;

$\mathrm{Y}$ las menores lumbres,

El resplandor perdido,

Se esconden a los ojos

Que observan sus caminos.

Del Tormes suena lejos

El desigual ruido,

Que forman las corrientes

Batiendo con los riscos.

$¡ \mathrm{O}$ invierno! ¡o noche triste!

¿Quan grato a mi tranquilo

Pecho es tu horror! jtu estruendo

Quan plácido a mi oído!... 
Podemos ver la influencia de James Thomson en el poeta extremeño en el tratamiento que dan uno y otro al sol; el escocés introduce su visión del sol con una personificación, en la que centra su atención explicando cómo la luz de éste es un símbolo fundamental del universo:

But yonder comes the powerful king of day

Rejoicing in the east, The lessening cloud,

The kindling azure, and the mountain's brow

Illumed with fluid gold, his near approach

Betoken glad. Lo! now, apparent ail,

Aslant the dew-bright earth and coloured air,

He looks in boundless majesty abroad,

And sheds the shining day, that burnished plays

On rocks, and hills, and towers, and wandering streams

High-gleaming from afar... ${ }^{29}$.

Meléndez Valdés, sin dejar de considerar al astro como símbolo del universo, lo reviste de un poder omnímodo sobre todo lo que existe bajo el cielo:

\section{AL MEDIO DÍA}

Velado el sol en esplendor fulgente

En las cumbres del cielo,

Lanza derecho ya su rayo ardiente

Al congojado suelo;

$\mathrm{Y}$ al medio rutilante ordena,

Que su rostro inflamado

Muestre a la tierra, que a sufrir condena

$\mathrm{Su}$ dominio cansado.

El viento el ala fatigada encoge

$\mathrm{Y}$ en silencio reposa,

Y el pueblo de las aves se recoge

A la alameda umbrosa

Cantando ufano en dulce caramillo

Su zagaleja amada,

Retrae su ganado el pastorcillo

A una fresca enramada;...

Otro ejemplo de imitación, posiblemente el más claro de todos en lo que a Thomson se refiere, lo tenemos en las Odas filosóficas y sagradas, en las cuales los temas predominantes son la naturaleza, la meditación del filósofo, y el sentimiento de Dios; podemos ver la influencia directa de Thomson en el poeta extremeño al comparar el inicio de Winter y la primera oda filosófica y sagrada, «El invierno es el tiempo de la meditación»:

\section{WINTER}

SEE, Winter comes to rule the varied year,

Sullen and sad, with all his rising train-

${ }^{29}$ Summer, vv. 81-90. La idea fundamental es señalar al sol como astro rey; pero, además, esta personificación tiene como objetivo ofrecer una visión de la naturaleza basada en el orden y la belleza. 


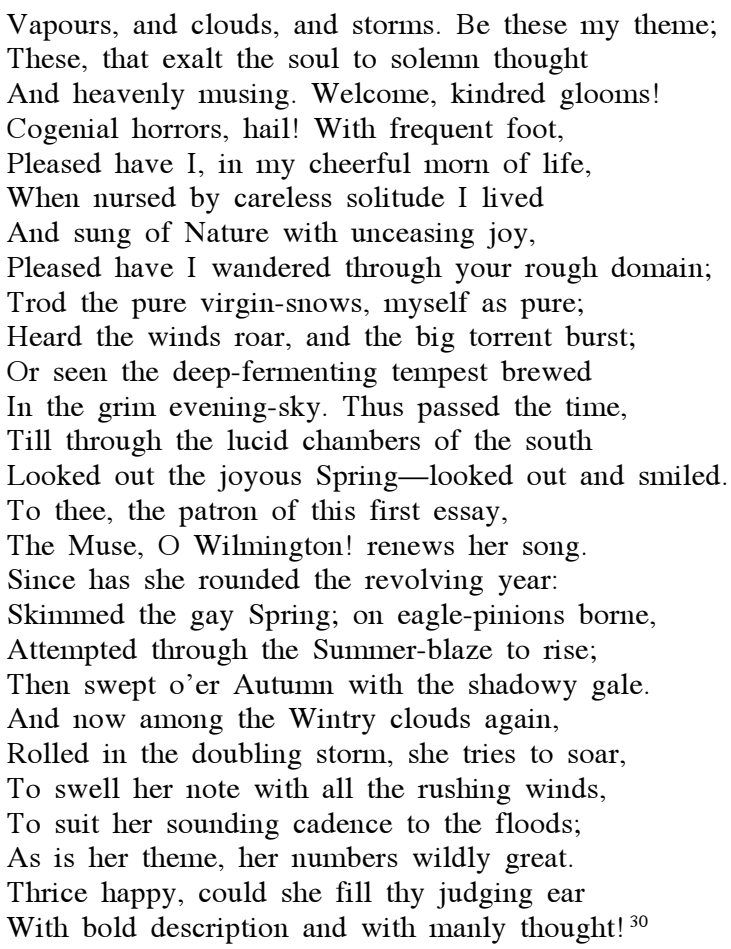

${ }^{30}$ La traducción española de los versos de Thomson nos muestra mejor la influencia del escocés en el extremeño:

«Mira, llega el invierno domando al voluble año, melancólico y triste, con su visible boato: nieblas, nubes, tormentas ¡Qué sean mi inspiración, que excitan en el alma solemnes pensamientos, divinas reflexiones! ¡Salve, amenas, tristezas, salve, amables horrores! Frecuentemente a pie, y contento, en mi alegre alborear de la vida, cuando vivía criado en libre soledad y Natura cantaba con alegría incesante, contento he caminado por tus campos indómitos; pisado nieves vírgenes, tan puras como yo; he oído soplar al viento, bramar al gran torrente; o visto la tormenta desafiante incubarse en el atardecer lúgubre. Así pasaba el tiempo, hasta que por las salas luminosas del sur, miraba a la gozosa Primavera y sonreía. A ti, que eres patrón de este primer ensayo, la Musa ¡Oh Wilmington! Renueva ya su canto. desde entonces cerró circular ciclo el año: rozó la Primavera; nacida en alas de águila, tratando de alzarse entre el ardor del verano; 
EL INVIERNO ES EL TIEMPO DE LA MEDITACIÓN

Est quadam prodire tenus, si non datur ultra ${ }^{31}$

Salud, lúgubres días, horrorosos

Aquilones, salud. El triste invierno

En ceñudo semblante

Y entre velos nublosos

Ya el mundo rinde a su áspero gobierno

Con mano asoladora: el sol radiante

Del hielo penetrante

Huye, que embarga con su punta aguda

A mis nervios la acción, mientras la tierra

Yerta enmudece, y déjala desnuda

Del cierzo alado la implacable guerra.

Falsos deseos, júbilos mentidos,

Lejos, lejos de mí: cansada el alma

De ansiaros días tantos

Entre dolor perdidos

Halló al cabo feliz su dulce calma.

A la penada queja y largos llantos

Los olvidados cantos

Suceden; y la mente que no vía

Sino sueños fantásticos, ahincada

Corre a ti, o celestial filosofía,

$\mathrm{Y}$ en el retiro y soledad se agrada.

¡Ah! ¡Cómo en paz, ya rotas las cadenas,

De mi estancia solícito contemplo

Los míseros mortales,

$\mathrm{Y}$ sus gozos y penas!

Quien trepa insano de la gloria al templo;

Quien guarda en su tesoro eternos males;

Con ansías infernales

Quien ve a su hermano y su felice suerte,

Y entre pérfidos brazos le acaricia;

O en el lazo fatal cae de la muerte,

Que en doble faz le tiende la malicia.

pasando luego rápido por el violento otoño.

Y ahora entre las nubes invernales de nuevo, envueltas en tormenta trata de alzar el vuelo, intenta hincharse con los vientos tempestuosos, regular sus ruidosa cadencia a las crecidas;

como en su propio hogar, su frecuencia abruma:

¡feliz podría tres veces extasiar los oídos

con osadas imágenes y rudas reflexiones!».

31 «Ya es algo llegar hasta cierto punto, si no es posible ir más allá». Horacio: Epistulae, 1, 1, 32. Es una idea muy parecida a la de Sextus Propertius: In magnis et voluisse sat est («En las grandes empresas, el haberlas intentado ya es bastante»), y que Lope de Vega transmitirá en La Imperial de Otón:

«Las cosas basta intentallas cuando son tan grandes ellas que es imposible acaballas». 


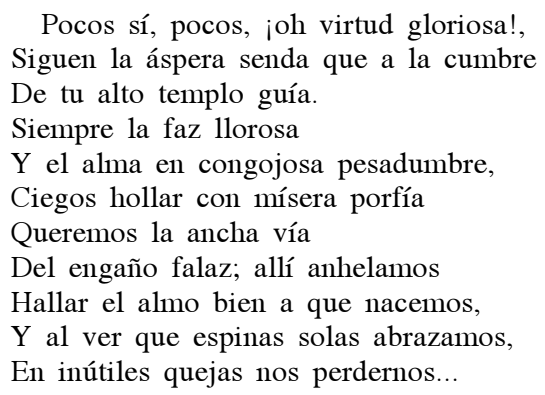

\section{CONCLUSIÓN}

Puede observarse que una parte sustancial de la poesía que escribe Meléndez desde su primera época, pero sobre todo en los últimos tiempos, adquiere un tono sentimental que preludia la mentalidad romántica. No llega, sin embargo, al empleo abusivo de estos recursos como ocurrirá décadas más tarde en pleno auge del Romanticismo. No pocos de estos poemas «sentimentales» tienen que ver con temas y lenguaje literario prestado por Garcilaso o Fray Luis. Sin embargo, otras influencias muy claras provienen de autores europeos que preludian el prerromanticismo e incluso el romanticismo inglés, sobre todo de autores que cultivan la poesía melancólica, intimista, filosófica y de pleno contacto con la naturaleza; digamos que la posición del poeta es la que determina la percepción de la naturaleza y el tratamiento que ésta recibe, a partir de su consideración como interlocutor, espejo, origen de sensaciones o mundo autónomo: el poeta se debate entre la retórica de la queja, la introspección y la contemplación más o menos científica.

En estos avatares de la naturaleza como material poético se haya el núcleo de la transformación del modelo clásico; en él, la naturaleza es ante todo un objeto de imitación, bien en su estricto papel de natura naturata (las cosas creadas), bien en su función de natura naturans (la fuerza creadora), siempre partiendo del principio de orden, armonía y estabilidad. Frente a ello, la naturaleza se convertirá en campo para la observación fenomenológica, ya sea en la corriente filosófica y estética del sensismo, ya sea como espacio para el despliegue de la sentimentalidad del sujeto provocada por la conciencia o la contemplación de una naturaleza que ya no se encierra en el tópico del locus amoenus pastoril, sino que se presenta como objeto de una experiencia real y cada vez más individualizada.

La secuencia de égloga clásica, idilio anacreóntico, poesía contemplativa (pasando por el beatus ille horaciano) y poesía de la naturaleza es representativa de estos cambios estéticos; todas ellas se dan en la trayectoria creativa de Meléndez y en ella hay que considerar, junto a los modelos estrictamente neoclásicos e ilustrados de procedencia francesa, otras influencias que 
apuntan a una nueva sensibilidad y que provienen de Inglaterra. Se trata de autores que inician una renovación en la poesía pastoril basada en Teócrito y Virgilio, pero añadiéndoles connotaciones de la filosofía de Locke, que pone el acento sobre la percepción de los sentidos y concede un lugar de privilegio a la visión, favoreciendo el don de la observación ${ }^{32}$. La confluencia de temas va a ser muy clara en el poema de James Thomson, The Seasons, y en los poemas filosófico-sagrados de Meléndez Valdés.

\section{BIBLIOGRAFÍA}

AA. VV., Los conceptos de Rococó, Neoclasicismo y Prerromanticismo en la literatura española del siglo XVIII, Oviedo, Cátedra, Feijoo, 1970

Abellán, José Luis, Historia crítica del pensamiento español. Del Rococó a la Ilustración (siglos XVII y XVIII), t. III, Madrid, Espasa Calpe, 1981.

ARCE, Joaquín, La poesía del siglo ilustrado, Madrid, Alambra, 1981.

ARCE, Joaquín, GLENDINNING, Nigel y DUPUIS, L., La literatura española del siglo XVIII y sus fuentes extranjeras, Oviedo, Cátedra, Feijoo, 1968.

Astorgano ABajo, Antonio, Biografía de D. Juan Meléndez Valdés, Badajoz, Diputación de Badajoz, 1996.

BARREL, John, English Literature in History 1730-80, London, Hutchinson, 1983.

CAMERON, Margareth, M., L'Influence des «Saisons» de Thomson sur la poésie descriptive en France (1759-1810), Paris, Honoré Champion, 1927.

CANO, José Luis, «Gessner en España», Heterodoxos y prerrománticos, Madrid, Júcar, 1974, pp. 191-227. (Publicado anteriormente en la Revue de Littérature Comparée, XXXV, 1961, pp. 40-60).

CARNERO, Guillermo, «La oposición entre el campo y la ciudad en Meléndez Valdés», Homenaje a José María Martínez Cachero. Investigación y crítica, Oviedo, Universidad, 2000, II, pp. 357-392.

CASALDUERO, Joaquín, «Las nuevas ideas económicas sobre la agricultura en el siglo XVIII y el nuevo sentimiento de la naturaleza», La Torre, 61, (1968), pp. 45-60.

CASO GONZÁlez, José Miguel, «La poesía comprometida de Meléndez Valdés», La literatura española de la Ilustración: Homenaje a Carlos III, Madrid, Universidad Complutense, 1989, pp. 53-73.

COLFORD, William E., Juan Meléndez Valdés. A study in the transition from Neo-Classicism to Romanticism in Spanish Poetry, New York, Hispanic Institute, 1942.

Cossío, José María, «Un dato de la fortuna de las Noches de Young en España», Boletín de la Biblioteca Menéndez Pelayo, V, 1923, pp. 344-345.

Cox, R. M., Juan Meléndez Valdés, New York, Twayne Publishers, 1974.

DEMERSON, Georges: «Sur seize odes d'Horace traduites par Meléndez Valdés», Bulletin Hispanique, LX, 1958, pp. 62-72.

${ }^{32}$ Un poema publicado en 1709 por Henry Grove: «A Hymn on Sight» es revelador de esta tendencia; el poeta, atento a captar todas las bellezas que se ofrecen a su vista, aprende a contemplar la naturaleza con ojos nuevos:

«I bless my God for ev'ry Sense,

But most for thee, my darling Sight,

By whom I learn t'Adore the Pow'r

That won this beauteous World from Night»(Poetical Miscellanies: The Sixth Part, London, J. Tonson, 1709, pp. 507-508). 
—, Don Juan Meléndez Valdés y su tiempo (1754-1817), 2 vols. Madrid, Taurus, 1971.

-, Esbozo de una biblioteca de la juventud ilustrada (1704-1808), Oviedo, Cátedra Feijoo, 1976.

ENCISO, Luis Miguel, «La Biblioteca de Meléndez Valdés», Barroco e Ilustración en la Bibliotecas Privadas españolas del siglo XVIII, Discurso de ingreso en la Real Academia de la Historia el día 17 de marzo de 2002, Madrid, 2002, pp. 183-186.

Esteban, José, Meléndez Valdés, Gijón, Ediciones Júcar, 1987.

FORCIONE, Alban, «Meléndez Valdés and the Essay on Man», Hispanic Review, XXXIV, 1966, pp. 291-306.

FRANZINI, Elio, La estética del siglo XVIII, Madrid, Visor, 2000.

FROLDI, Rinaldo, Un poeta illuminista: Meléndez Valdés, Milano, ed. Cisalpino, 1967.

GESSNER, Salomon, Euvres complètes, nouvelle édition, revue et corrigée avec le plus grand soin, 3 vols., Orléans, Rouzeau-Montaut, Imprimeur du Roi, 1783.

—, Idilios en castellano, trad. de M. A. Rodríguez, Madrid, Sancha, 1799.

IGLESIAS, M. ${ }^{\text {a }}$ Carmen, Razón y sentimiento en el siglo XVIII, Madrid, Real Academia de la Historia, 2001.

JACOBS, Helmut C., Belleza y buen gusto. Las teorías de las artes en la literatura española del siglo XVIII, Madrid, Iberoamericana, 2001.

Kenwood, A., «The Seasons and Some of Their Sources in Meléndez Valdés», Australasian Universities Language and Literature Association, ed. de J. R. Ellis, Melbourne, University, 1971, pp. 464-483.

LÓPEZ ESTRADA, Francisco, Los libros de pastores de la literatura española, Madrid, Gredos, 1974.

MARAVALL, José Antonio, La estimación de la sensibilidad en la cultura de la Ilustración, Madrid, Instituto de España, 1979.

MELÉNDEZ VALDÉs, Juan, Poesía, edición, prólogo y notas de Pedro Salinas, 5ª ed., Madrid, Espasa Calpe, 1973.

—, Poesías, edición, estudio y notas de Emilio Palacios, Madrid, Alhambra, 1979.

-, Obras en verso, edición crítica, prólogo y notas por J. H. R. Polt y G. Demerson, Oviedo, Cátedra Feijóo, Centro de Estudios del Siglo XVIII, 1981.

-, Poesías, Oviedo, Pentalfa Ediciones, 1989

—, Poesías, edición de César Real Ramos, Madrid, Espasa Calpe, 1991.

-, Antología poética, prólogo Miguel Ángel Lama, Badajoz, Corporación de Medios de Extremadura, 2003.

MÉRIMÉE, Paul, L'influence française en Espagne au dix-huitième siècle, Paris, Les Belles Lettres, s/d.

MONTIEL, Isidoro, «El connubio Young-Ossian en la lírica de Juan Meléndez Valdés y Nicasio Álvarez Cienfuegos», Ossian en España, Barcelona, Planeta, 1974, pp. 74-78.

PalaCios, Emilio, «Los poetas de nuestro Siglo de Oro vistos desde el XVIII», II Simposio sobre el P. Feijoo y su siglo, Oviedo,1976.

POLT, John H. R., «La imitación anacreóntica en Meléndez Valdés», Hispanic Review, 47, 1979, pp. 193-206.

-, Batilo: Estudios sobre la evolución estilística de Meléndez Valdés, Oviedo, Centro de Estudios del Siglo XVIII, 1987.

—, «Meléndez, Traductor», Estudios Dieciochistas en homenaje al profesor José M. Caso González, Oviedo, Instituto Feijoo, 1995, II, pp. 263-265.

PRADO, Javier del, «La imagen de Francia en el diálogo epistolar de Jovellanos, Meléndez Valdés y Moratín» (Homenaje al Prof. Jesús Cantera, Servicio de Publicaciones Universidad Complutense, Madrid, 1997, pp. 243-256).

RODRÍGUEZ DE LA FLOR, Fernando, «Convencionalismo y artificiosidad en la poesía bucólica de la segunda mitad del s. XVIII», Boletín del Centro de Estudios del siglo XVIII, 9, 1983, pp.184-200. 
—, «La filiación neoplatónica de un poema de Meléndez Valdés», Dieciocho, 3, 1980, pp. 51-61.

—, «Aportaciones al estudio de la escuela poética salmantina (1773-1789)», Studia Philologica Salmanticensia, 6, 1982, pp. 193-229.

SALINAS, Pedro, «La poesía de Meléndez Valdés», Ensayos de Literatura Hispánica, Madrid, Aguilar, 1967, pp. 236-272; reproducido en Ensayos completos, edición de Solita Salinas de Marichal, Madrid, Taurus, 1983, I, pp. 60-90.

SAlvador, Gregorio, El tema del árbol caído en Meléndez Valdés, Oviedo, Cátedra Feijoo, 1966.

SEBOLD, Rusell P., «Sobre la lírica y su periodización durante la Ilustración española», Hispanic Review, 50, 1982, pp. 297-326.

—, El rapto de la mente. Poética y poesía dieciochescas, Barcelona, PPU, 1989.

—, Lírica y poética en España, 1536-1870, Madrid, Cátedra, 2003.

ThOMSON, James, Las estaciones del año, poema de Jayme Thompson [sic], traducido por D. Benito Gómez Romero, presbítero, Madrid, Imprenta Real, 1801, 2 vols.

ToDD, Janet, Sensibility. An Introduction, London, Methuen, 1986.

Trigueros, Cándido María, Apuntaciones sobre los idilios de Gessner, Biblioteca Nacional, Mss. 18.072, núm. 18.

Fecha de recepción: 11 de diciembre de 2006

Fecha de aceptación: 26 de julio de 2007 